\title{
REVISIONES
}

\section{Educación matricial, patrimonios en suspensión vital}

\author{
Matricial education, patrimony in vital suspension
}

\author{
Roberto Marcelo Falcon, ${ }^{a}$ Apolline Torregrosa ${ }^{a b}$
}

\author{
${ }^{a}$ Universidad Paris Descartes \\ Telf.: (33) 643730237. Correo electrónico: marcelo.falcon@ ceaq-sorbonne.org \\ 'Telf.: (33) 642785133. Correo electrónico: apolline.torregrosa@parisdescartes.fr
}

\begin{abstract}
RESUMEN
Este artículo nos invita a comprender la educación patrimonial desde la perspectiva de la sociología comprensiva, es decir, como experiencia matricial que pone en juego las estructuras antropológicas del imaginario. Donde las vivencias colectivas y artísticas nos inician fuera de un pensamiento histórico, introduciéndonos dentro de una dimensión holística del saber y del mundo. Así la experiencia patrimonial o matricial ligada a procesos educativos, sensibles y artísticos, revela la existencia de los aspectos oscuros de los pueblos, de los grupos de personas, entendidos como comunidades unidas por un destino común. Desde esta situación, la experiencia educativa como experiencia comprensiva, matricial o patrimonial, nos invita a mirarnos fuera del tiempo lineal, interrumpiendo el olvido, cesando lo desencantado, suspendiendo lo estático y vinculándonos a los palimpsestos vivos que nos ofrece el tiempo alabeado por lo afectivo. Finalmente, podemos comprender la existencia de una educación matricial como dimensión copulativa, creativa o anómica, como territorio fértil, como potencia que propicia el renacimiento permanente de un pluralismo creador. Inmersos en este ambiente, los procesos formativos y matriciales, se experimentan como intensos procesos digestivos, ya que propician transformaciones con todos los elementos sustanciales de las historias colectivas.
\end{abstract}

Palabras clave: sociología comprensiva, imaginarios, experiencia formativa, matriz, anomia.

\begin{abstract}
This article invites us to understand patrimonial education from the perspective of comprehensive sociology, that is, as a matrix experience that puts at stake the anthropological structures of the imaginary in which the collective and artistic experiences initiate us outside of a historical thought, introducing us within a holistic dimension of the knowledge and of the world. Thus the patrimonial or matrix experience linked to educational, sensitive and artistic processes reveals the existence of the dark aspects of the peoples, of the groups of people, understood as communities of destiny. From this situation, the educational experience as a matrix or patrimonial experience, invites us to look outside the linear time, interrupting the forgetfulness, ceasing the disenchantment, suspending the static and linking to the living palimpsests offered by time warped by the affective. Finally, we can understand the existence of a matricial education as a copulative or anomic dimension, as a fertile territory, as a force that promotes the permanent revival of creative pluralism. Immersed in this environment, the formative and matrix processes are experienced as intense digestive processes, as they promote transformations with all the substantial elements of collective histories.
\end{abstract}

Keywords: sociology comprehensive, imaginary, experience, matrix, anomic. 


\section{LA EDUCACIÓN PATRIMONIAL DESDE LA SOCIOLOGÍA DEL IMAGINARIO}

Pensar la educación patrimonial desde la sociología del imaginario es subrayar la dimensión sensible que les liga, es comprender la existencia de un vínculo que se extiende fuera de las lógicas racionales e históricas. Recordando los trabajos de Gilbert Durand (1992) que valoraba el imaginario más allá del espíritu racional campante en el pensamiento occidental, le entendemos como una vía de evitar el dualismo establecido en la visión del conocimiento y del mundo. A partir de las estructuras antropológicas del imaginario, notamos la importancia de revalorizar la dimensión imaginal dentro del patrimonio y este, como resonancia de aquel. Más allá de las clasificaciones o los criterios construidos racionalmente en torno al patrimonio, es necesario introducir la parte sensible, obscura, secreta y mítica que los fundan. Pensar los imaginarios como estructura más o menos visible del patrimonio, nos traslada a la obra de Durand, quién en la continuación del trabajo de Gaston Bachelard (1948), ha desarrollado una lectura antropológica del imaginario, la cual tiñe todas las relaciones cotidianas. Es decir, volver a dar el lugar a los imaginarios desde una perspectiva sociológica, dentro de una cultura iconoclasta que rechaza la imagen como forma de conocimiento. Esta dualidad que se instauró desde nuestra herencia judeocristiana y se acentuó en nuestro pensamiento moderno, separa la imagen y lo sensible de lo racional. En efecto, lo sensible está asociado al error, a un camino de la ilusión y apartándole hemos dejado el lugar libre a la sobrevaloración de la razón como único medio para llegar al conocimiento. Es por ello que el patrimonio se apreció desde criterios principalmente históricos, culturales (nacionales) y científicos. De este modo, se consideró que se favorecería la adquisición de conocimientos, contribuyendo el patrimonio a una construcción cultural de reconocimiento de huellas pasadas dejadas por nuestros antepasados. El patrimonio, desde esta situación, se destacó como poder de la ciencia, de la razón, de la ilustración, que omitió radicalmente la dimensión sensible, secreta e, incluso, inconsciente y oscura. Evidentemente, el patrimonio no se estimó desde la experiencia sensible, desde las interrelaciones de personas y sus relatos, sino que subrayó su carácter testimonial histórico, participando de una construcción social racional. Desde la ilustración, se ha desplegado para impregnar todos los campos de la vida humana y, particularmente, como transmisión de saberes desde lo histórico. Este espíritu sigue presente, especialmente en ese afán de transmitir el patrimonio desde su historia, pero que hoy se empieza a vislumbrar su diversidad en la participación de actividades pedagógicas y artísticas. Esta realidad evidencia la reintegración de la dimensión sensible, de las estructuras antropológicas del imaginario en el aprendizaje del patrimonio.

Al haber priorizado la razón ante lo sensible, se ha reducido de la esencia social y del conocimiento científico los mitos, las creencias, las supersticiones y las potencias narrativas de los pueblos. Realidades que nos llevan a redimensionar al patrimonio como origen y amplificación de conocimientos, además, de experimentarle como fuente antropológica e imaginal del mundo. Porque dejando lugar a la razón histórica, nos hemos alejado de la naturaleza viva de las cosas y situaciones, de los arquetipos sensibles que les sustentan. Es en esta búsqueda de saberes amplificados, al integrar aquello marginado por la razón extrema, que se nos revela un mundo no dominado por la lógica científica, es decir, un universo social y cultural que poco a poco incluye los aspectos imaginarios y no solamente cuantificables. Dentro de este contexto, la dimensión mágica tiene lugar visible, dando importancia a los misterios de la existencia, a las realidades místicas que están en la base 
del patrimonio. Nuestra necesidad de clasificar y organizar cada elemento de la vida desde lo inteligible, ha sido un potente instrumento de comprensión, pero también de reducción que desmitificó todas las áreas disciplinares; realidad que ha reducido el patrimonio, minimizando los procesos afectivos y ocultos, para construir un conocimiento simplificado $\mathrm{y}$ accesible. Es decir, se ha pensado el patrimonio en ausencia de las complejidades de las relaciones personales, en ausencia de las efervescencias que están en su origen. Indudablemente, al revertir esta realidad, el patrimonio ampliado se visibiliza en su real completitud, es decir, desde la presencia latente de los imaginarios.

En este sentido, el patrimonio instaurado desde una perspectiva racional para constituir un saber común, propio de una nación, de una cultura, ha sido un camino de transmisión y de irradiación de poder de unos sobre los otros. Si el concepto de patrimonio encuentra su origen y dirección en este espíritu dualista y reductor, marcará los sitios, eventos y festividades dignas de devenir representante de una cultura de un modo racional. Pero deslizándonos hacia un paradigma comprensivo que integra lo imaginal, el patrimonio se transfigura en una oportunidad matricial, es decir, de renacimiento continuo, de trayecto enigmático, de experiencia fértil, de travesía viva y colectiva. En este sentido, las actividades pedagógicas y entonces la educación patrimonial, se transforma en experiencia creadora y matricial, que nos invita a sumergirnos en las potencias arquetipales de las comunidades de destino.

\section{A PARTIR DE UN PENSAMIENTO ARQUETIPAL}

Imbricando lo imaginal y lo patrimonial se despliegan experiencias sustentadas en un pensamiento profundo y vivo, es decir, en un pensamiento arquetipal que nos inicia en un modo de conocer fuera de una linealidad histórica, al margen de un control reductor de la riqueza social. En efecto, la dualidad del pensamiento moderno que reduce la complejidad del mundo, se fundamenta en la separación de lo acaecido para comprenderle. En este sentido, aparta fechas, personas ilustres, lugares memorables, dejando al margen secretos, narraciones y lo que podemos entender como la dimensión obscura de lo relacional, de las relaciones sociales, de la cultura; sin embargo, los imaginarios tanto diurnos como nocturnos están en el origen de las civilizaciones, de todos los caos creativos, abriendo posibilidades de creación cultural e impulsando al mismo tiempo el desarrollo de las inteligencias individuales y colectivas. Es aquí que la unión íntima entre imagen, palabra, silencio y memoria teje aquello que comúnmente en las comunidades se llama patrimonio. Donde las experiencias y los sentidos compartidos son esenciales en estos procesos de gestación social, integrando relatos de lo ausente y lo presente, redescubriendo así un patrimonio múltiple, heterogéneo, que revela el claro oscuro del estar juntos. Aquí los imaginarios, el pensamiento imaginal creado colectivamente, es el soporte de la vida mental de las comunidades, una potencia espiritual que le dinamiza, que actúa como una fuerza en suspensión que se transmite incesantemente provocando resonancias sociales (Durand, 1992).

Indudablemente, acotar el patrimonio a la dimensión histórica es propio del reduccionismo racionalista que denunciaba Durand. Porque los imaginarios y lo arquetipal forman una capa profunda en nuestros pensamientos y actos, revelando la potencia de lo inconsciente, de lo onírico, de lo simbólico, sin descuidar la fertilidad de las imágenes, lo 
cual nadie puede obviar sin mutilarse. Por lo tanto, los imaginarios están presentes en todas situaciones, más aún en el patrimonio, ya que deviene el substrato de lo cotidiano y todo aquello que nos rodea. El patrimonio desde un pensamiento arquetipal e imaginal posibilita pensarle y experimentarle simultáneamente como una realidad amplificada que nos inicia en otras dimensiones de lo real, que nos impulsa a migrar hacia sus pliegues sensibles, hacia un saber aumentado y fecundo. Viaje enriquecido por todas las pequeñas historias personales e, indudablemente, acrecentadas por las experiencias artísticas que integra en ellas mismas, las sombras de lo relacional. Estos trayectos curvos o complejos hacen de la experiencia patrimonial una oportunidad creadora, por ende, matricial, que ofrece la oportunidad de nacer colectivamente en un saber dinámico, atractivo y encantado.

En este estadio podemos situar el patrimonio en una dimensión arquetipal e imaginal (Falcón \& Torregrosa, 2013), que eyecta orígenes anómicos, que genera una ruptura radical en relación con ciertos hábitos comunitarios. Desde ello, estamos ante la presencia de un pensamiento y tendencia colectiva que circula naturalmente, inconscientemente, reconformando lo cotidiano. Esta contra dirección discreta del patrimonio invita a las personas a vivir la experiencia extraordinaria de estar juntos, fuera de lo normativo, por lo tanto, dentro de lo vital. Lo arquetipal, imaginal y anómico craquea lo liso, provocando la emergencia de infinitas aberturas que estimulan a las comunidades a reencantarse desde lo profundo y lo superficial, desde lo secreto y lo evidente. Aquí y según Duvignaud (1990), lo anómico designa la aparición de intersticios entre dos fuerzas, que hacen emerger lo inesperado, la creación y todo aquello que escapa a lo controlado desde lo institucional. Como consecuencia, lo anómico es lo que propicia giro de épocas, de pensamiento, de prácticas y es lo que potencia la emergencia de imaginarios colectivos. Lo patrimonial, ahora entendido como una fuerte corriente anómica, matricial y creadora, imprime en el carácter de los pueblos su potencia imaginal. Fuera del reconocimiento institucional, de toda legitimación legal, la fuerza imaginal de las colectividades revela incesantemente aquello que late en silencio, como la excitación arquetipal. Pensar la educación patrimonial como fuerza anómica y matricial nos hace vivenciar el origen de los vínculos, el principio de las interacciones entre las personas que fortalecen las comunidades. Fuera de lo desencantado por la razón, por un pensamiento histórico, es posible vivir los arquetipos en lo cotidiano, habitarles, entrar en contacto con ellos y, ciertamente, compartirles. Religarse con esta energía creadora encarnada en las diferentes situaciones del día a día, implica comprender también nuestras vidas personales, que incluyen todos aspectos oscuros, secretos e inexplicables. Estas reservas inconscientes que conforman el patrimonio, lejos de ser una claridad agradable, la luz de un saber condensado generacionalmente, constituyen la dimensión obscura de las culturas. Aquí es donde también se delata la existencia de los arquetipos personales y colectivos, por ende, las luces y las sombras de un respirar juntos ancestralmente.

Indudablemente, para pensar el patrimonio desde lo arquetipal e imaginal, necesitamos recordar su inicio desde el siglo de las luces, la ilustración, entendiendo todo aquello que acentuó la importancia de proteger y preservar los bienes culturales al servicio del pueblo. Un pasado que se legaba y que permitía reconocer los diferentes pasos de la humanidad. Esto constituye el pensamiento moderno que nos sitúa en una historia lineal, estable y objetiva, que fragmenta las dimensiones humanas para presentarlas controladas. A través del patrimonio como orden consciente, es la historia en su grandeza que se presenta como única y dominante de nuestras relaciones, de nuestras narraciones. Pero hablar del patrimonio como experiencia subterránea, arquetipal, imaginal, como viaje matricial, nos 
lleva a un pensamiento anómico que no implica una historia única, sino multitudes de relatos que se transforman fundamentalmente en lo clandestino y artístico. Entender el patrimonio como vida fecunda y compleja siempre nos liga a Edgar Morín, quién subraya que lo complejo es justamente lo que se teje juntos, realidad en la cual incorporamos lo sensible, lo artístico. En este sentido, la experiencia artística en lo patrimonial es un dinamismo que dibuja otros estadios sociales, un pasaje anómico y sensible que hace posible circulaciones cotidianas no evidentes. Desde esta realidad, podemos repensar las acciones artísticas formativas integrando las experiencias y relatos oscuros, generando experiencias colectivas y artísticas que nos pongan en contacto con las estructuras afectivas e instintivas que unen las personas. Estamos ante rituales siempre intersticiales que hacen de los encuentros cotidianos una liturgia creadora, un diálogo instintivo que nos sorprende y que reaviva el patrimonio arquetipal.

\section{DE LO PATRIMONIAL A LO MATRICIAL}

Actualmente, estamos inmersos en un pasaje, en un deslizamiento de una educación patrimonial a una matricial, es decir, de procesos de aprendizajes anclados en una linealidad histórica dirigida por grupos de poder, a procesos de comprensión creativa en torno a las potencias sensibles de las personas. En este sentido, pasamos de una relación estática a una dinámica del conocimiento, de una acumulación de información a inculcar a los otros a experiencias de descubrimiento sensible que nos ligan a los demás. Estamos ante la presencia de un pensamiento sensible, orgánico o vitalista que impulsa la presencia de experiencias que no solamente toman contacto con un conocimiento e información ya existente, sino que son matriz creativa de saberes y nuevas relaciones. Esta situación es evidentemente una realidad matricial, ya que es dinámica y hace nacer procesos de aprendizajes y creación de conocimientos a través del descubrimiento colectivo, artístico y sensible. Es esta relación compleja entre personas, narraciones, imaginarios la que hace emerger otras formas de entender y entenderse que llamamos matriciales y copulativas, por ende, creadoras y creativas.

En este sentido, hemos realizado experiencias artísticas de descubrimiento de la riqueza cultural e histórica en el Château de Peyrelade, sitio patrimonial en Aveyron (Francia). Los visitantes, un público familiar, eran invitados a realizar una experiencia de puesta en común de su situación presente desde una actividad de creación colectiva artística con las piedras del entorno y, finalmente, a partir de sus narraciones, encontrar colectivamente la vida de las personas que habitaron el lugar y las diversas situaciones históricas (Falcón \& Torregrosa, 2009). Partir del presente, de lo cotidiano y los arquetipos vivos, puso en interacción y resonancia a las personas a partir de una experiencia artística colectiva. Dicho de otro modo, es posible poner en relación las diversas situaciones de la vida de las personas que buscan los patrimonios, con las diferentes realidades históricas, vivenciales y ambientales. Esto devela la posibilidad de comprender el pasado, el legado histórico patriarcal desde las potencias arquetipales culturales, desde las realidades de las personas, para hacer nacer otras visiones del patrimonio, hecho que revela la existencia de una educación matricial. Por lo tanto, el deslizamiento de un aprendizaje racional del patrimonio hacia la comprensión sensible del mismo, subraya la transformación de la educación patrimonial en formación matricial, es decir, de lo estático en lo dinámico, de la memoria muerta a la viva y activa, de la razón a la razón sensible. 
El patrimonio desde la experiencia sensible puede ser sentido y comprendido como una vivencia colectiva que nos mantiene en un estado de creación permanente o dimensión matricial que crea y redescubre los lazos sociales. Si el patrimonio es entendido desde una visión principalmente racional, patriarcal dominante, necesariamente se aleja de las realidades sensibles de las personas. Por ello, la educación como formación matricial hace posible acercarnos de otro modo al legado histórico. La educación patrimonial basada en la transmisión de bienes materiales e inmateriales comunes a unas personas, que olvida las realidades cotidianas de las mismas, hace honor al origen etimológico del término, es decir, a una fuerza patriarcal o ley del padre que presiona desde lo alto. Así se asegura aquellas ideas que hay que conocer, respetar, transmitir y que deben perdurar a lo largo de la historia. Esta lógica del deber ser subrayada por Max Weber, revela que el espíritu de la ilustración continua actualmente, a través de pedagogías, metodologías y diferentes ideas fuerza que mantienen la separación entre la luz de la razón y la penumbra u oscuridad de la creación sensible. Por ello, hemos vivenciado e invitamos a vivir una educación creadora o matricial, es decir, propuestas pedagógicas que abren vías de experiencias que nos hagan participar de un vivo patrimonio arquetipal, enraizado en las potencias sensibles de los colectivos. Fuera de un pensamiento racional ilustrado, pensamos en experiencias que nos permitan respirar lo profundo, lo inconsciente y los imaginarios presentes de todo patrimonio. Este no se reduce a su historia construida, sino a las vivencias, creencias y procesos creativos que le han impulsado desde su origen. La parte anómica del patrimonio que le engendra se revela sorpresivamente en las potencias colectivas de las personas que le visitan.

Por lo tanto, lo matricial percibido como experiencia de creación grupal, como oportunidad de encontrar nuevamente los canales creadores, nos invita siempre a unir intelecto y sensibilidad. Es decir, a conformar procesos creativos desde una inteligencia colectiva y afectiva, que reúnen lo cotidiano y la naturaleza, que propician el retorno del saber al hábitat natural. Inmersos en ello, estamos ante trayectos aglutinantes que nos convocan a desplegar formas naturales e instintivas del estar juntos, de conocer y de crear fuera de todo control racional. Esta realidad revela la existencia de una errante y térrea inteligencia colectiva, que hace posible la reinvención de la existencia por sumersión en el patrimonio natural cultural, vivido ahora como experiencia matricial, creadora, anómica, sorprendente e indómita. Dentro de este dinamismo es posible desplegar las potencias personales y colectivas, ingresando en un mundo que se desarrolla orgánicamente fuera de toda construcción o imposición racional. Implicados en una realidad compleja y amplificada por lo sensible, por lo artístico y lo colectivo, brota un activo pensamiento copulativo, vislumbrado como fuerza intelectual y afectiva que engendra mundo. Esta fuerza intelectual y sensible que crea desde lo heterogéneo impulsa el continuo renacimiento de los grupos societales, aquellos que se despliegan subterráneamente en un instintivo silencio creador.

La vivencia del patrimonio como experiencia matricial no solamente es una lenta sedimentación de conocimientos, de memorias conservadas y transmitidas, sino también una fuerte ruptura epistemológica, que hace nacer otra forma de respirar e irrigar el presente relacional y el mundo heredado. Maffesoli subraya esta noción de ruptura:

Il est fréquent chez les grands penseurs qu'une illumination engendre une rupture dans la manière de penser. Cela se fait, d'ailleurs, dans la crainte et le tremblement. Mais le changement est alors net, brutal, total. Euclide, Newton, Pascal, Nietzsche ... la liste est longe des eurêkas ponctuant les grandes découvertes. (2010, p. 133). 
El pensamiento creador como dinamismo copulativo, encarnado en las experiencias memoriales, es una corriente que rompe con un conformismo habitual, que da sabor al saber cultural y aviva el despliegue de las personas. Este pensamiento, emergente desde la energía vital colectiva, implica fuertes correspondencias entre lo auditivo, táctil, visual, olfativo y gustativo que, ligado a las memorias y a la creación de conocimiento, fragiliza las certezas y los contenidos culturales confinados en objetivos construidos, en fines edificados fuera de las sensibilidades y ebulliciones societales. Son estas rupturas cortocircuitos que activan las fuerzas copulativas y matriciales, que nos ponen en contacto con un vivo inconsciente colectivo, con potencias incisivas y discretas que constituyen el pensamiento progresivo de los pueblos, en las palabras de Maffesoli (2015). Progresión de un saber ancestral, copulativo y creador, que impulsa a las comunidades a entregarse en un destino común, conformando colectivos creativos alejados de toda reducción racial o étnica. Desde este escenario, el pensamiento copulativo y sus fuerzas matriciales, nos invitan a generar rupturas e intersticios para participar en grupos societales creativos que amplifican lo que se es en comunidad. Comprender la educación matricial como proceso creador, es otorgar al conocimiento su dimensión holística, es decir, sensible, artística, colectiva y simbólica. Realidad que es posible ligar al mito de la digestión según Bachelard (2011), es decir, como trayecto de generación, de creación y de comprensión, que innegablemente cambia el espíritu científico de una época. En ello, lo digestivo, asociado a la creación, la formación y la investigación, implica colectivas experiencias matriciales que dan nacimiento y vida a los imaginarios de los pueblos. Según Bachelard, debemos tener en cuenta tres digestiones para desarrollar el espíritu científico de una época: una ligada a la tierra, donde se transforman los elementos naturales; otra a la cocina, donde las personas transforman estas potencias de la natura; y, finalmente, el estómago que continúa este viaje de mutaciones para ofrecer lo necesario para el organismo. En este sentido, la educación matricial o patrimonial y la creación de conocimiento pueden ser entendidas como una digestión copulativa que hace posible el desarrollo de las personas y sus comunidades. Este proceso digestivo y copulativo lo entendemos como mezcla de lo diverso y participación en experiencias patrimoniales, que logran crear y recrear el imaginario de las comunidades. Esto propicia una incesante lluvia de orígenes, de comienzos colectivos en los que quedan integrados lo instintivo, lo sensible, lo artístico, lo consciente y lo inconsciente de las sociedades. Es así que lo matricial se revela como proceso digestivo, copulativo y anómico, es una experiencia creadora que funda los imaginarios comunes, desplegándose mientras queda sustentada en las profundidades inconscientes de las personas. A partir de ello, la educación matricial puede ser vista como una fuerza telúrica, sensible, copulativa, capaz de reavivar incesantemente los imaginarios en los cuales las personas habitan.

Fuera de un monoteísmo patriarcal, arrogante y pretencioso, la experiencia artística matricial nos sumerge en un pluralismo vital y sensible, que se revela como un umbral creador, como una vía ajena de toda fuerza dogmática. Experiencia que vive fuera de la perennidad de métodos, ya que no confía en los hábitos intelectuales. Solamente por ello, nos incita a realizar descubrimientos sin crear posteriormente reglas y así ingresar en zonas de asimilación de lo desconocido. Tal situación evita, por estrecho o reductor, el pensamiento objetivo, haciendo germinar un pensamiento teórico y experimental errante que genera un saber no rehén de proyectos incuestionables. La experiencia matricial como aventura creadora se entrelaza permanentemente con la fecundidad primera de las comunidades y grupos societales, con sus orígenes vivos. Este escenario nos muestra que asistimos a un 
deslizamiento de lo patrimonial a lo matricial, que mezcla y transmuta el conocimiento, lo artístico, los procesos educativos y de investigación, junto a las memorias e imaginarios de las personas. Vivir esta digestión destinal, entendida como metamorfosis de lo diverso que crea destino común, es participar de un viaje cultural que pone de manifiesto las potencias imaginales y matriciales de los pueblos, sus fuerzas telúricas o nocturnas, las realidades arquetipales que les conforman. Son estas sensibles estructuras sociales, fuerzas matriciales que ofrecen un espacio de ebulliciones y nacimientos, que ponen en suspensión activa todo lo que se es y será. Se concibe así la suspensión activa como potencia imaginal en estado latente y, simultáneamente, en un permanente estado de actualización desde las relaciones cotidianas, aleatorias e inconscientes. Comprender el estado suspensivo y activo de los imaginarios, como estructura creadora y fundadora de lo social, es entender que la memoria colectiva es parte de estas estructuras sociales. Aquí la colectiva vida imaginal, latente y actualizada en lo ordinario, participa de las transfiguraciones de las comunidades, por lo tanto, de sus procesos digestivos matriciales en permanente estado creador fuera de lo dogmático. Esta digestión creadora logra evitar la higienización racional que construye diversas identidades, ofreciendo como alternativa un pluralismo imaginal, un bricolaje arquetipal y sensible que da sentido vital a la experiencia cotidiana.

El pluralismo metodológico y experimental que ofrece la educación matricial o patrimonial, basada en lo artístico y sensible, cuestiona la existencia desde la imagen, desde la vivencia colectiva, desde lo onírico e inconsciente. Despliega un pensamiento visual y artístico no prisionero de lo verbal, que hace posible la amplificación y digestión comprensiva del mundo. Inventa canales de comunicación, creación, investigación, educación, es decir, de modos de estar juntos desde una inmersión comprensiva. Dentro de este deslizamiento comprensivo, la educación matricial celebra nacimientos, vivifica y genera un saber artístico que impulsa errancias colectivas. Realidad que nos inicia en un mundo afectivo paralelo al normativo, pero que puede clandestinamente invitarlo a girar matricialmente. Este contexto es nómade, anómico y holístico, ya que involucra todas las disciplinas, provocando una comunidad de destino. Pensamos que ante toda reestructuración instintiva de lo social, entendida como transfiguración matricial de sus realidades, nacen aquellos fundamentos sensibles y afectivos que ligan fielmente a las personas, que les actualizan como las fuerzas fecundas y copulativas. Estas potencias vivas o copulativas impulsan una silenciosa y gigantesca digestión imaginal, que va conformando el destino de las comunidades. Aquí las memorias son un ingrediente sustancial, ofreciendo un pluralismo creador o matricial, ya que donan el tesoro escondido y anómico que estructura los pueblos.

\section{ESTRUCTURAS NOCTURNAS DE LO MATRICIAL}

Este pasaje de lo patrimonial a lo matricial, de lo infértil a lo fértil, nos invita a vivir, a contactar con las aguas profundas y creadoras de la cultura. Desde lo subterráneo es posible actuar y reflexionar creativamente sobre nuestro presente, donde lo artístico es una vía mágica que nos pone en contacto con las profundidades olvidadas que organizan lo social. Las situaciones ordinarias, teñidas de lo afectivo, implican un retorno a las estructuras sensibles que organizan las relaciones personales. El teatro del día a día, las circunstancias no planificadas, son la puerta de entrada a una fecunda riqueza colectiva que va conformando 
la vida social. La inmersión en esta teatralidad errante e incontrolada de lo ordinario nos sitúa lentamente en las profundidades oscuras donde se incuba la superficie de todo lo visible. Descender en estas cavernas desde las situaciones habituales es iniciarse en un viaje de reencuentro con lo olvidado, con aquellas latencias que dan vida a estas realidades usuales. Enriquecidos por esta experiencia matricial de lo cotidiano, los educadores artistas investigadores, atentos a ello, se revelan como pasadores de un pensamiento artístico (Falcón, 2016) que reinventa las relaciones habituales, el conocimiento y los procesos de indagación. Este ambiente vivo y creador hace que la experiencia matricial aumente, acrecentando la comprensión y recreación del mundo, poniendo en suspensión activa las capacidades imaginales y simbólicas de las personas. Vivencia que nos eyecta fuera de todo conformismo intelectual, de todo aislamiento infértil, introduciéndonos en el interior de un devenir creativo ligado a las memorias e imaginarios colectivos. Participar de esta caverna fértil, intimidad fermental o experiencia matricial, nos lleva al corazón de los pueblos, a este horno donde se fragua su destino. En estas profundidades digestivas, obscuras y discretas, en este vientre incubador, en estas aguas prenatales, se sienten y se escuchan las manos creadoras de las personas, se percibe la presencia activa de lo ausente. El destino común desde lo matricial hace de los procesos formativos y la investigación una interioridad creadora que es capaz de reconstituir permanentemente las estructuras del imaginario social.

Desde una mirada antropológica, Durand (1992, p. 217) establece que la estructura de repetición implica preservación o fidelidad a la esencia primitiva de los pueblos; la estructura afectiva revela una adhesividad instintiva entre las personas; la estructura mística hace posible la creación o conformación de nuevos objetos y ritos; y finalmente la estructura de lo ínfimo nos invita a vivir lo pequeño o insignificante como microcosmos que exhiben meticulosos detalles de las relaciones sociales. Desde tal mirada, la preservación, lo afectivo, lo creativo y lo ordinario son parte de la estructura matricial que conforma las relaciones sociales. Las estructuras matriciales dan fuerza a la teatralidad cotidiana, participando de un proceso digestivo o de transformación afectiva, creativa e íntima, que facilita la permanente reconformación de lo social. Dentro de esta realidad, la experiencia matricial constituye una oportunidad de forjar lo que será y de proteger la esencia de las comunidades de destino. La educación matricial, consciente de ello, vive fuera de las verdades de laboratorio, de la ilustración, respira al margen de un patrimonio impuesto dogmáticamente y, por lo tanto, crece dentro de una digestión compleja que sostiene el imaginario social. Aquí la fuerza racional no desmitifica e invalida las aguas matriciales de los pueblos, sino que participa de su continuo retorno.

La experiencia educativa y artística desde lo matricial se desarrolla integrando las personas desde sus pulsiones afectivas, creativas, repetitivas y cotidianas, implicando procesos de inmersión en las profundidades imaginales de las sociedades. Lo matricial mantiene en suspenso activo un conocimiento colectivo que circula incesantemente, que se revela insistentemente en cada ritual formativo. Aumenta el saber a través del sabor imaginal de la experiencia y acrecienta el patrimonio imaginal de la humanidad. La experiencia como pensamiento copulativo o matricial genera procesos formativos que no buscan un conocimiento verdadero, sino un saber mutante y errante que invite a conocer de otro modo el mundo. Fuera de realidades estáticas, emerge un dinamismo existencialmatricial que sustenta las estructuras flexibles de lo social. La permanente creatividad que ello implica, hace de la experiencia una travesía colectiva en la errancia, donde lo creado, 
lo conformado y lo reinstaurado, conjuga lo consciente, lo inconsciente, lo revelado y, finalmente, lo emergente por lenta digestión del saber. Desde esta visión, la educación matricial es una suspensión activa que reinventa desde la teatralidad ínfima de lo cotidiano y lo formativo, la completitud sensible del mundo.

\section{SUSPENSIÓN MATRICIAL}

Escapar de la vigilia extrema de todo lo dogmático a través de las experiencias matriciales, copulativas e imaginales, nos lleva a comprender por inmersión en lo cotidiano, las potencias vivas de lo colectivo. Aquí las relaciones frecuentes se revelan como una fuerza perenne, como una energía que hace posible la reinvención al margen de los poderes de turno. Tales dinamismos adquieren carácter de un fuera de juego que invoca lo anómico, es decir, las emergencias sorprendentes externas al poder de los administradores políticos. Nacen así miríadas de alternativas, dando refugio afectivo a las personas, salvándolas de la intemperie árida de las sociedades modernas. Esto supone una inmigración de un estadio de reducciones a otro de amplificaciones creadoras, de un territorio seco a uno húmedo. Por ende, en este pasaje de lo patrimonial a lo matricial se visibiliza un viaje de lo controlado, analítico e infértil a lo anómico y copulativo. Salir del control a la creación desde las potencias instintivas y arquetipales de las personas, fuera de toda previsión, amplía las relaciones creadoras y todas sus resonancias. Una necesaria educación matricial hace referencia a este proceso creador, a un viaje de inmigración interdisciplinar que se desplaza de lo infértil a lo fértil, evidenciando un continuo retorno a las potencias memoriales de los pueblos que se despliegan incesantemente fuera de todo control o proyecto. La inmigración matricial de las memorias colectivas implica procesos de aprendizajes que transfiguran las fragilidades de lo identitario, convirtiéndoles en potencias vivas, es decir, en múltiples identificaciones intersticiales que transforman lo aislado en lo ligado. Indudablemente, estamos ante una alternativa a todo control administrativo, por ende, ante un sendero que nos invita a desplegarnos creativamente en un destino común.

Escapar de lo aislado de un sí mismo personal e identitario hacia experiencias de identificación con lo complejo, nos sumerge en un nosotros que se revela como una potencia central y recreativa, como una energía sagrada que reencanta el destino colectivo. Aquí la saturación de un yo que controla deja paso a un nosotros anómico creador, entendido como una fuerza que condensa fértilmente. Es así como es posible aventurarse lejos de toda imposición, ingresando en espacios donde el pensamiento copulativo, creador y anómico puede desplegarse naturalmente. Situación que se revela como alternativa a todo camino incuestionable, a toda postura que establece lo que es y lo que no es. La educación matricial como experiencia creadora es una llamada de auxilio que nos lanza lejos de todo simulacro social, de toda relación contractual, haciendo posible las relaciones sensibles y sinceras. Ya dentro de la experiencia matricial, participamos de una revolución que no busca ningún tipo de explotación, ningún estadio de poder, de gobierno, de control, sino que susurra naturalmente la sustancia pasional de las estructuras sociales. Discreción que va reconfigurando las apariencias de las relaciones cotidianas, que va revelando la fertilidad de lo heterogéneo, que va impulsando la fuerza creadora de las personas y que pone en suspensión activa las memorias vivas de los pueblos. Reconfigurar la vida desde las experiencias matriciales es fluir siempre hacia territorios de comunión entre lo conocido y lo 
desconocido. Situación que ofrece el reencuentro de un presente rico en sustratos ofrecidos por el pasado y que reencanta los encuentros ordinarios y el conocimiento, poniendo en escena las potencias creativas de las personas. Este espectáculo hace de las apariencias, de la fugacidad, esporas nutritivas, resonancias que nos seducen y nos invitan a participar de la estructuración social, de la estructura teatral de lo social. Son estos rituales cotidianos, un fundamento sensible o base no lógica de lo racional según Maffesoli (1998). En ello, la teatralidad cotidiana, las potencias activas y sensibles de las personas fundan lo social. En definitiva, estamos ante una realidad fértil que vive al margen de toda conducta consciente de anticipación, que escapa de una existencia proyectiva hacia otra natural y mística.

\section{APERTURA}

Finalmente, la educación matricial es una dimensión copulativa y anómica donde todas las comunidades de destino pueden recrearse desde las experiencias sensibles, afectivas, instintivas y cotidianas que ofrece. Estamos ante un territorio fértil, ante una fuerza creadora que propicia el renacimiento permanente de la energía sensible que aglutina los grupos sociales. El pluralismo creador que está en el sustrato de la educación matricial es una potencia viva o suspensión activa que irriga y multiplica las estructuras patrimoniales que fundamentan lo social. En estos escenarios se incuba el destino personal y colectivo, un devenir vivo que preserva, sensibiliza, crea y da significados a todo aquello aparentemente sin interés o marginado por el racionalismo extremo. Inmersos en este ambiente, los procesos formativos son matriciales y se experimentan como intensos procesos digestivos, ya que propician transformaciones con todos los elementos sustanciales de las historias colectivas. Esta realidad eyecta una lluvia incesante de orígenes creadores, incluyendo la emergencia y asimilación de un conocimiento distinto, de un saber errante no rehén de lo controlado. Este pensamiento colectivo es siempre un viaje orgánico que pone en suspensión activa la esencia de las comunidades de destino. De este modo, la educación matricial concibe canales creadores interdisciplinares, haciendo de la investigación un trayecto que sinceramente asimila lo desconocido fuera de terrenos normativos o dogmáticos. La inmersión en la formación como iniciación matricial es una aventura anómica que fragiliza certezas en todas las áreas de conocimiento, recreando el estar juntos en lo cotidiano, en lo cultural y en la investigación. Aquí las potencias vivas de lo colectivo fomentan un contagio creativo que integra las memorias colectivas, favoreciendo un natural y holístico destino común. La educación matricial participa de un deslizamiento de época, invitando a las personas a desplegarse fuera de pensamientos fijos, por lo tanto, inmersas en trayectos dinámicos, flexibles, sensibles y artísticos. Prácticas que nacen desde la participación en un mundo heterogéneo que evita la homogeneización del saber, donde la experiencia patrimonial como fuerza matricial o copulativa, implica los aspectos oscuros de las personas y las culturas.

\section{REFERENCIAS BIBLIOGRÁFICAS}

Bachelard, G. (1948). La terre et les rêveries du repos. Paris: Corti, Les Massicotés. Bachelard, G. (2011). La formation de l'esprit scientifique. Paris: Vrin. 
Durand, G. (1992). Les structures anthropologiques de l'imaginaire. Paris: Dunod.

Duvignaud, J. (1990). Herejía y subversión. Barcelona: Icaria éditorial.

Falcón, R. M. (2016). La pensée artistique par la recherche sensible. Sociétés, Revue des sciences humaines et sociales ( ${ }^{\circ}$ 131, pp. 131-139). Bruxelles: De Boeck éditions.

Falcón, R. M., \& Torregrosa, A (2009). Educación y patrimonio: Cultura de la recepción y visitación. Revista Ibero-Americana de Pesquisa em Educaçao, Cultura e Artes. Recuperado desde https:// issuu.com/invisibilidades/docs/invisibilidades_0

Falcón, R. M., \& Torregrosa, A (2013). Patrimonios instintivos. En R. Huerta \& R. De la Calle (Coords.), Patrimonios migrantes (pp. 125-132). Valencia: Universidad de Valencia.

Maffesoli, M. (1998). La conquête du présent. Paris: Desclée de Brouwer.

Maffesoli, M. (2010). La République des bons sentiments. Perpignan: Éditions Embrasure.

Maffesoli, M. (2015). Le trésor caché. Paris: Éditions Léo Scheer. 